\title{
A study on efficacy of limbal relaxing incisions in correcting corneal astigmatism along with clear corneal phacoemulsification in a tertiary eye care centre in South India
}

\author{
K. Ravikumar ${ }^{1}$, M. Arthi $^{2}$, Rajakumari ${ }^{3}$ \\ ${ }^{1}$ Dr. K. Ravikumar, Associate Professor, ${ }^{2}$ Dr. Arthi. M, Postgraduate, ${ }^{3}$ Dr. Rajakumari, Professor, all authors are \\ affiliated with Regional Institute of Ophthalmology Government Ophthalmic Hospital, Egmore, Chennai, Tamil Nadu, \\ India
}

Address for Correspondence: Dr. K. Ravikumar MS, Associate Professor, Regional Institute of Ophthalmology Government Ophthalmic Hospital, Egmore, Chennai. Email ID: krkeyedr@gmail.com

\begin{abstract}
Aim: The main aim of this study was to study the effectiveness of limbal relaxing incisions in correcting corneal astigmatism when combined with clear corneal phacoemulsification. Materials and Methods: 50 eyes of 37 patients satisfying the inclusion and exclusion criteria were included in the study. After adequate pre operative workup, all patients underwent limbal relaxing incisions coupled with clear corneal phacoemulsification. The incisions were calculated based on Gills nomogram. Postoperative visual acuity and corneal topography were performed to assess the correction of corneal astigmatism. Results: The mean age of our study population was $57.08 \pm 10.07$ years. 50 eyes of 21 males and 16 females were included in our study. The mean preoperative Uncorrected Visual Acuity was 1.0 with a standard deviation of 0.5 (in $\log \mathrm{MAR}$ ) and the best spectacle corrected visual acuity was 0.8 with a standard deviation of 0.4. The postoperative uncorrected visual acuity at 4 weeks $0.0 \pm 0.15$ with a best corrected visual acuity was $0.09 \pm 0.1$. At 12 weeks, uncorrected visual acuity was 0.0 with a standard deviation 0.07 . There was $71.8 \%$ decrease in central corneal astigmatism after limbal relaxing incisions. Conclusion: Therefore we conclude that limbal relaxing incisions can be used effectively in conjunction with cataract surgery to reduce the astigmatism <3 D at the corneal level and aids us in providing spectacle free optimal distance vision in patients.
\end{abstract}

Keywords: Limbal relaxing incision, Corneal astigmatism, Gills nomogram

\section{Introduction}

The aim of modern day cataract surgery is to provide a spectacle free optimal distant vision in patients [1]. This has led to the evolution of cataract surgery as a refractive surgery as well. Intraocular monofocal lenses correct spherical component of the refractive error but the astigmatic component remains uncorrected. There are various methods for correction of astigmatism at the corneal level - both non surgical and surgical. Non surgical methods include spectacles and contact lenses. Surgical methods to correct astigmatism include limbal relaxing incisions and implantation of toric intraocular

Manuscript received: $04^{\text {th }}$ February 2017

Reviewed: $12^{\text {th }}$ February 2017

Author Corrected: $18^{\text {th }}$ February 2017

Accepted for Publication: $28^{\text {th }}$ February 2017 lenses [2]. Toric IOLs depict a precise and reliable method of correcting astigmatism but has a steep learning curve and is expensive. Limbal relaxing incisions provide a reliable alternative for correction of mild to moderate corneal astigmatism. Though toric IOLs are preferred for high levels of astigmatism $>4.00$ $\mathrm{D}$, Limbal relaxing incisions are a safe and effective procedure in expert hands leading to rapid visual rehabilitation. LRIs involve placement of relaxing incisions along the steeper axis of the cornea which leads to subsequent flattening along that axis [3].

Purpose- The main aim of this study was to study the effectiveness of limbal relaxing incisions in correcting 
corneal astigmatism when combined with clear corneal phacoemulsification. This was determined by comparing preoperative and post operative uncorrected visual acuity, keratometry and topographic analysis.

\section{Materials and Methods}

This was a prospective study which was conducted at Regional Institute of Ophthalmology and Government Ophthalmic Hospital from February 2016 to September 2016. Fifty eyes of 37 patients were included in the study.

\section{Inclusion Criteria}

1. Patients with regular corneal astigmatism from $1.5 \mathrm{D}$ to $3 \mathrm{D}$ were included in the study.

2. Patients with significant cataract ( group II - IV according to the Lens Opacities Classification Systems III) [4]

3. Patients more than 50 years of age

4. Axial length of the eye ball between $23-25 \mathrm{~mm}$.

\section{Exclusion Criteria}

1. Previous history of ocular surgeries.

2. Irregular astigmatism.

3. Peripheral corneal thinning

4. Extremely steep corneas with K reading more than $47 \mathrm{D}$.

5. History of other ocular diseases ( uveitis, optic nerve and macular disorders ,glaucoma etc.,)

All the patients underwent detailed ophthalmic examination. Pre operative evaluation included recording Uncorrected Visual Acuity (UCVA), Best Spectacle Corrected Visual Acuity (BSCVA) using Snellens visual acuity chart. Intraocular pressure measurement using Goldman's applanation tonometer was done. The axial length was measured using A scan and the keratometry reading was done using manual keratometer and autokeratometer. The intraocular power of the lens was finally calculated using the Sanders- Retzlaff -Kraff T formula (SRK - T). The corneal topography was done using computerized videokeratoscopy to reassess the keratometric reading and to determine the exact orientation of the steep axis for the placement of LRI during surgery. A detailed slit lamp examination was done to rule out any eye pathologies and fundus assessment using Slit lamp biomicroscopy with a $+90 \mathrm{D}$ lens and indirect ophthalmoscopic examination was performed. The same experienced surgeon performed all the surgeries either under topical anaesthesia or under peribulbar block. The size and the location of the limbal relaxing incision were determined by the Gills nomogram [5]. Paired $6 \mathrm{~mm}$ incisions are required for astigmatism upto 2D. To correct astigmatism between $2-3 \mathrm{D} 8 \mathrm{~mm}$ incisions are required. The incisions are placed at the steep axis in the limbus just anterior to the surgical limbus. A 600 micron pop up micrometer blade is used for this purpose (Image 1). LRIs were customized according to the corneal topography of the patient (Image 2).

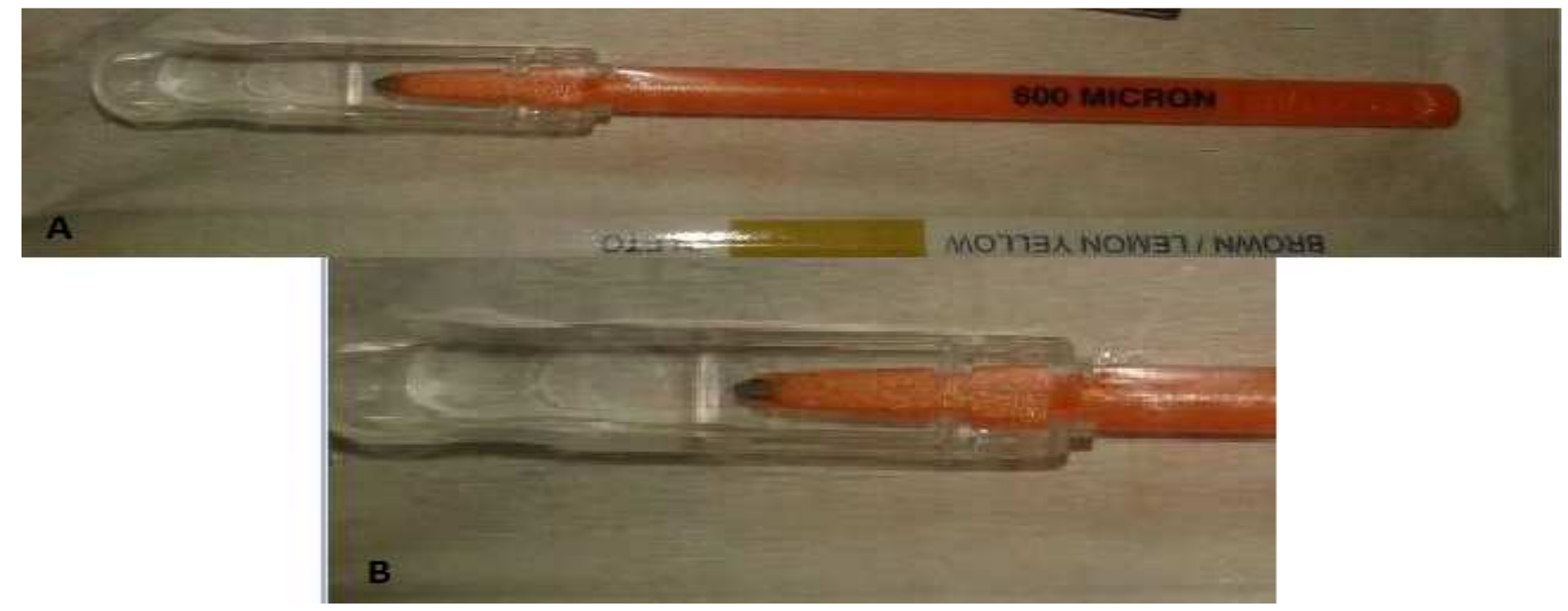

Figure 1: A, B 600 micron pop up micrometer blade for performing Limbal relaxing Incisions 
After the limbal relaxing incision was made clear corneal incision was made along the steepest axis and monofocal foldable IOL was implanted with emmetropia as the goal of surgery. There was no intra operative or post operative complications. None of the cases required suturing of the wound.

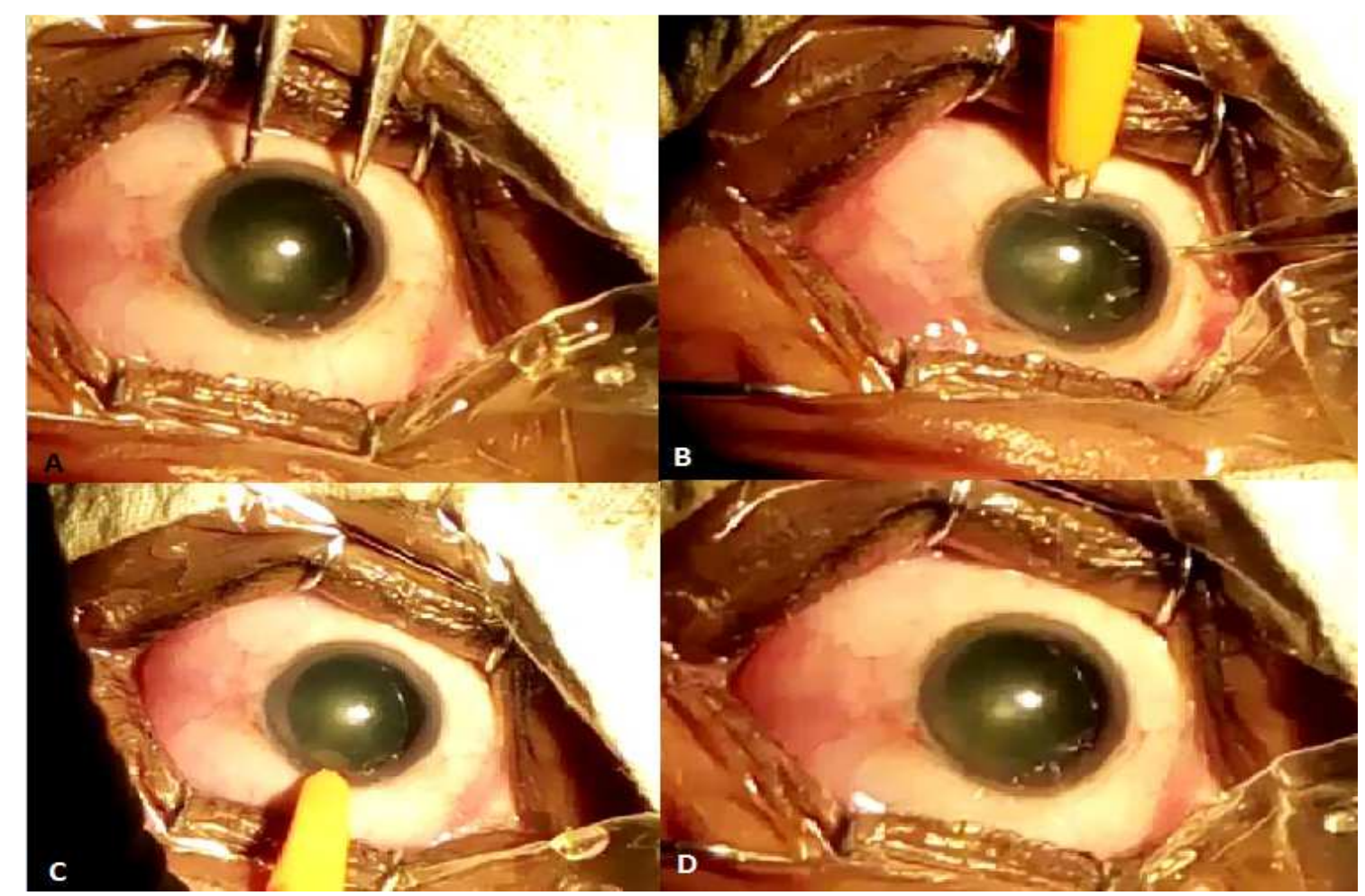

Figure 2: A. measuring $6 \mathrm{~mm}$ using Castroviejo calipers along the steepest meridian. B,C two paired 6 mm incision made along the steepest meridian using 600 micron pop up blade. D. Intraoperative picture after making the limbal incision before making a clear corneal entry.

Patients were evaluated post operatively at day one, one week, one month and three months. Un corrected Visual Acuity, best Spectacle corrected visual acuity and Intraocular pressure were documented during each visit. Corneal topography and keratometry were performed at one and three months and this was considered for the statistical analysis (Image 3 ).
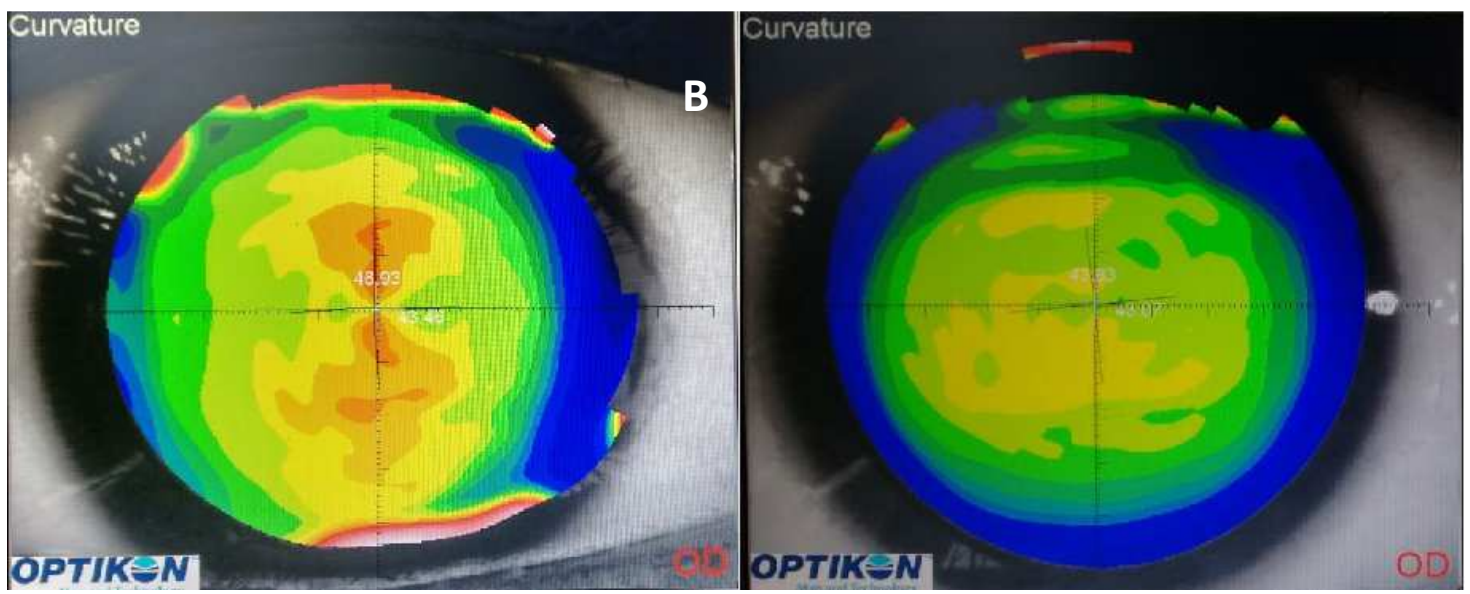

Figure 3: A. Preoperative with the rule astigmatism is demonstrated by a symmetrical bow tie pattern with the $\mathrm{K}$ reading of +43.46 diopters in the horizontal meridian and +46.93 in the vertical meridian. B. Neutralization of astigmatism postoperatively by limbal relaxing incision with $\mathrm{K}$ reading of +43.07 in the horizontal meridian and 43.33 in the vertical meridian. 


\section{Results}

A total of 50 eyes of 37 patients who came to Regional Institute of Ophthalmology and Government Ophthalmic Hospital for cataract surgery were included in this study. After undergoing the aforementioned ocular examination and investigations patients were taken up for cataract surgery. Among our study subjects 21 patients were males and 16 patients were females. The mean age of our study population was 57.08 years with a standard deviation of 10.7 years. The mean axial length of the eyes included in our study was $22.09 \pm 2.05 \mathrm{~mm}$. The average IOL power implanted in our study was $22.40 \mathrm{D}$ with a standard deviation of $1.1 \mathrm{D}$. the demographics of our study population are depicted in table 1.

Table-1: Demographic pattern of the study population

\begin{tabular}{|c|c|}
\hline Characteristics & Data \\
\hline Eyes (R/L) & $50(23 / 27)$ \\
\hline Mean Age & $57.08 \pm 10.7$ Years \\
\hline Sex (M/F) & $21 / 16$ \\
\hline Mean IOL & $22.4 \pm 1.1 \mathrm{D}$ \\
\hline Mean Axial Length & $22.09 \pm 2.05 \mathrm{~mm}$ \\
\hline
\end{tabular}

The mean diopteric power of the central cornea before surgery at presentation was $+44.20 \mathrm{D}$ with a standard deviation of $0.5 \mathrm{D}$. The mean diopteric power of the cornea at 4 weeks after surgery was $43.60 \pm 1.3 \mathrm{DD}$ and at 12 weeks was $43.50 \pm 1.2 \mathrm{D}$. The mean astigmatic power of the central cornea before surgery was $2.48 \pm 4.2 \mathrm{D}$. At 4 weeks after surgery, the mean astigmatic power of the cornea was $0.8 \pm 0.5 \mathrm{D}$ and $0.7 \pm 0.4 \mathrm{D}$ at 12 weeks after surgery (Table 2, figure 1,2 ). There was $71.8 \%$ decrease in corneal astigmatism after limbal relaxing incisions. The statistical analysis of the central corneal diopteric power using ANOVA (Analysis of Variance) was found to be statistically significant $(\mathrm{p}<0.01)$. The analysis of central corneal astigmatism at 4 weeks and 12 weeks was not found to be statistically significant (table 3 ).

Table -2: Mean diopteric power and astigmatic power of the cornea preoperatively and postoperatively

\begin{tabular}{|c|c|c|}
\hline & Mean Diopteric Power & Mean Astigmatic Power \\
\hline Pre-op Visit & $44.20 \mathrm{D} \pm 0.5 \mathrm{D}$ & $2.48 \pm 4.2 \mathrm{D}$ \\
\hline 4 Weeks Postop & $43.60 \pm 1.3 \mathrm{D}$ & $0.8 \pm 0.5 \mathrm{D}$ \\
\hline 12 Weeks Postop & $43.50 \pm 1.2 \mathrm{D}$ & $0.7 \pm 0.4 \mathrm{D}$ \\
\hline
\end{tabular}

Table-3: Statistical analysis of the mean astigmatic power of the cornea

\begin{tabular}{|c|c|c|c|c|c|}
\hline & Sum of Squares & df & Mean Square & F & Sig. \\
\hline Between Groups & 61.000 & 2 & 30.500 & 99.404 & .000 \\
\hline Within Groups & 45.104 & 147 & .307 & & \\
\hline Total & $\mathbf{1 0 6 . 1 0 4}$ & $\mathbf{1 4 9}$ & & & \\
\hline
\end{tabular}

The mean preoperative Uncorrected Visual Acuity was 1.0 with a standard deviation of 0.5 (in $\log$ MAR) and the best spectacle corrected visual acuity was 0.8 with a standard deviation of 0.4 . The postoperative uncorrected visual Acuity 
was 0.1 with a standard deviation 0.2 at 1 week whereas the Best Spectacle Corrected Visual Acuity 0.09 with a standard deviation of 0.13 .

Table 4: visual acuity pre op, 1 week, 4 weeks and 12 weeks post operatively. $N$ refers to the sample size

\begin{tabular}{|c|c|c|c|}
\hline Group & & UCVA & BCVA \\
\hline \multirow[t]{4}{*}{ Preoperative } & Mean & 1.0 & 0.8 \\
\hline & $\mathrm{N}$ & 50 & 50 \\
\hline & Std. Deviation & 0.51 & 0.4 \\
\hline & Median & 0.8 & 0.7 \\
\hline \multirow[t]{4}{*}{1 week } & Mean & 0.1 & 0.09 \\
\hline & $\mathrm{N}$ & 50 & 50 \\
\hline & Std. Deviation & 0.2 & 0.13 \\
\hline & Median & 0.2 & 0.1 \\
\hline \multirow[t]{4}{*}{4 weeks } & Mean & 0.0 & 0.0 \\
\hline & $\mathrm{N}$ & 50 & 50 \\
\hline & Std. Deviation & 0.15 & 0.1 \\
\hline & Median & 0.2 & 0.1 \\
\hline \multirow[t]{4}{*}{12 weeks } & Mean & 0.0 & 0.0 \\
\hline & $\mathrm{N}$ & 50 & 50 \\
\hline & Std. Deviation & 0.07 & 0.06 \\
\hline & Median & 0.0 & 0.0 \\
\hline
\end{tabular}

Table-5: Showing the statistical analysis of visual acuity between various groups

\begin{tabular}{|c|c|c|c|c|c|c|}
\hline \multicolumn{2}{|c|}{} & Sum of Squares & df & Mean Square & F & Sig. \\
\hline \multirow{2}{*}{ UCVA } & Between Groups & 21.637 & 2 & 10.819 & 113.991 & $\mathbf{0 . 0 0 0}$ \\
\cline { 2 - 7 } & Within Groups & 13.951 & 147 & .095 & & \\
\cline { 2 - 7 } & Total & 35.589 & 149 & & & \\
\hline BCVA & Between Groups & 18.060 & 2 & 9.030 & $\mathbf{0 . 0 0 0}$ \\
\cline { 2 - 7 } & Within Groups & 8.421 & 147.631 & & \\
\cline { 2 - 7 } & Total & 26.482 & 149 & & & \\
\hline
\end{tabular}


The postoperative uncorrected visual acuity at 4 weeks $0.0 \pm 0.15$ with a best corrected visual acuity was $0.0 \pm 0.1$. At 12 weeks, uncorrected visual acuity was 0.0 with a standard deviation 0.07 (Table 4, Figure 4). The difference between the visual acuity preoperatively and post operatively was found to be statistically significant with a $\mathrm{p}<0.01$ by employing the statistical test Analysis of Variance (ANOVA). The difference in visual acuity at 4 weeks and 12 weeks was not statistically significant $(\mathrm{p}>0.05)$ (Table 5).

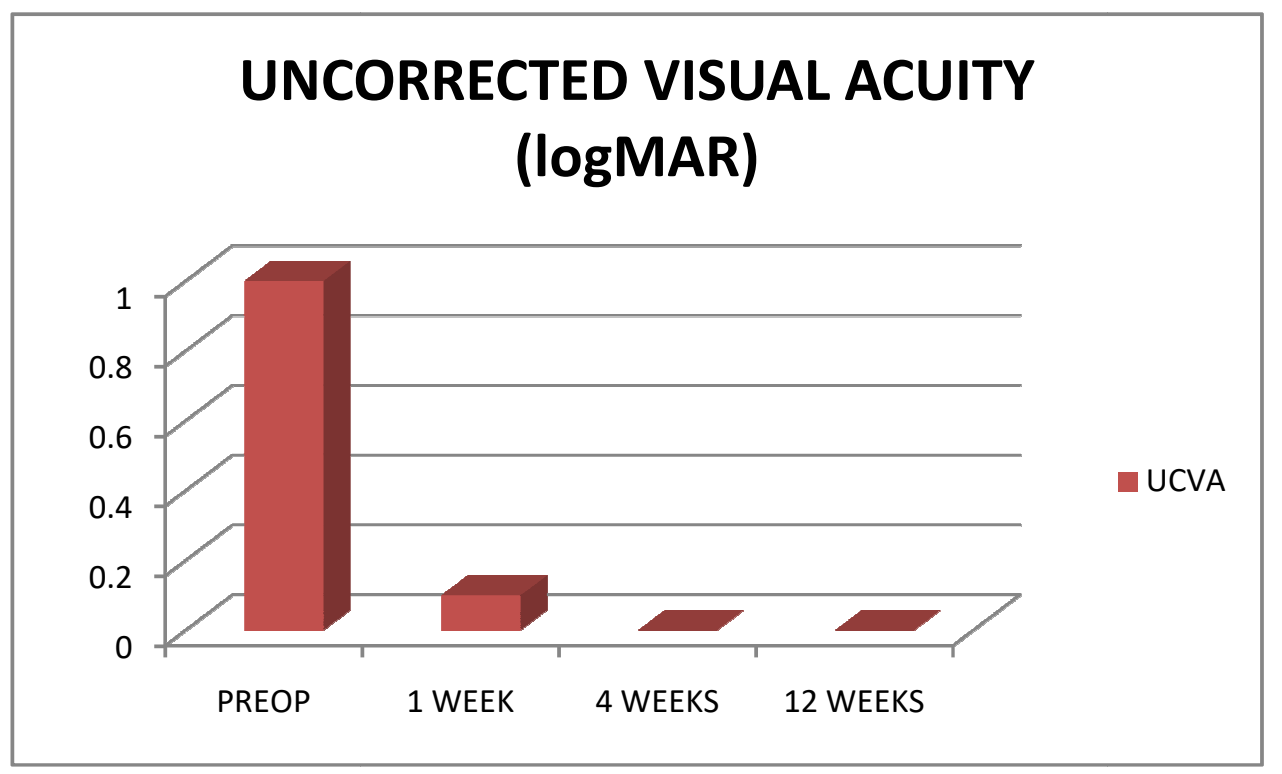

Figure-4: Uncorrected visual Acuity preoperatively and postoperatively

\section{Discussion}

Cataract surgery has currently become the most commonly performed refractive surgery and its ubiquity has given the surgeons ample opportunity to redefine the outcomes with great precision. Advancements in preoperative diagnostic tests and surgical techniques, as well as increased availability of premium intraocular lens (IOL) implants, have escalated patient expectations, thus making accurate management of preexisting astigmatism mandatory in order to deliver optimal visual outcome. Astigmatism management in cataract surgery is a well-studied issue, and many techniques are available for its correction, namely limbal-relaxing incisions (LRIs), arcuate keratotomies, toric intraocular lenses (IOL), paired incisions on the steep axis or subsequent excimer laser ablation (bioptic). It has been reported that $20 \%$ of all cataract patients have clinically significant astigmatism, usually $>1.5 \mathrm{dpt}$ [6]. Though Limbal relaxing incisions are known to be effective in correcting corneal astigmatism upto 4

diopters, recent studies indicate that it can be used reliably to correct corneal astigmatism upto the level of 2.5 D. It works well when performed during phacoemulsification and can be used independently to correct surgically induced astigmatism as well [7].

Compared to corneal relaxing incisions, limbal relaxing incisions are forgiving procedures with less post operative glare, discomfort and faster healing. It preserves the optical quality of the cornea and surgeons achieve excellent results even in their early procedures [5].

The placement of the LRI should be customized according to the topography of every patient. In cases of asymmetric astigmatism, the LRI in the steepest axis can be elongated slightly and shortened the same amount in the flatter of the two steep axes. Paired LRI's do not have to be made in the same meridian. If the topography reveals non-orthogonal astigmatism, each of the LRI's are placed at the steepest portion of the bow tie [5].

Overcorrections are unusual - it is much more likely for under correction to occur. Limbal relaxing incisions are also known to have a neutral effect on corneal aberrations [7]. Another study revealed quatrefoil aberration was significantly increased in the limbal 
relaxing incision group but not in the control group, with no significant difference between the two groups regarding corneal aberrations. There was no significant change in the other higher order corneal astigmatisms in both the study group and the control group.

There have been case reports of Limbal relaxing incisions being effective in patients undergoing combined cataract and glaucoma surgery [8]. The success of this combination in this case was attributed by the author to 2 factors. Either the induced astigmatism with the scleral flap incision was greater and/or the relaxing incision corrected more astigmatism than expected. Maybe both mechanisms coexisted. We must keep in mind the variable nature of both these procedures when performing them; in any case, a great reduction of astigmatism will be achieved. But extensive studies are required to ascertain its efficacy in such combined procedures.

Limbal relaxing incisions are found to be as effective as toric IOLs and extended on axis incisions in correcting corneal astigmatism $[9,10]$. On axis incisions are basic approaches for correcting corneal astigmatism, with simplicity being their main advantages over other incisional techniques. They involve extending the surgical wound created on the steep meridian to correct he corneal astigmatism. The effect of extended on axis incisions can be enhanced by creating a limbal relaxing incision just opposite the main wound. The main disadvantage of this approach is the need for wound suturing and extended follow-up examination resulting in slower visual recovery which can last a few weeks until complete suture removal. Additionally, if one end of an incision is closer to visual axis, an asymmetric correction will take place resulting in the shift toward this end of the wound. This is overcome by the application of paired limbal relaxing incisions which does not necessitate wound suturing. Toric IOLs yield more predictive results than other approaches and do not require additional corneal incisions, hence hastening visual recovery. One major complication is IOL rotation that can result in residual astigmatism and is expensive when compared to other methods of correction of astigmatism. The relaxing incisions are an economical alternative to toric IOLs and aid us in providing optimal visual outcome even in patients belonging to the lower socioeconomic group.

There are no reports of association of infectious complications or increase in their incidence when cataract surgery is performed in conjunction with limbal relaxing incisions.

Thus LRI preserves the perfect optical qualities of the cornea and is an excellent option for low-to-moderate degrees of astigmatism in a planned single bioptic procedure. The forgiving nature of LRI is due to placement and length of the incision. LRI produces lesser effect than corneal relaxing incision (CRI), thus precise alignment of the axis is not as critical. Carvalho et al. have shown that LRI performed during phacoemulsification surgery is a safe, effective, and stable procedure to reduce pre-existing corneal astigmatism [1].

\section{Conclusion}

Therefore we conclude that limbal relaxing incisions are a cost effective alternative to Toric IOLs and can be used in conjunction with cataract surgery to reduce moderate astigmatism at the corneal level and aids in providing spectacle free optimal distance vision.

\section{Funding: Nil, Conflict of interest: None. Permission of IRB: Yes}

\section{References}

1. Carvalho M, Suzuki S, Freitas L, Branco B, Schor P, Lima A. Limbal Relaxing Incisions to Correct Corneal Astigmatism During Phacoemulsification. J Refract Surg.2007; 23: 499-504. doi: 10.3928/1081-597X20070501-14.

2. Müller-Jensen K, Fischer P, Siepe U. Limbal relaxing incisions to correct astigmatism in clear corneal cataract surgery. J Refract Surg. 1999 Sep-Oct;15(5):586-9

3. Bayramlar H, Dağlioğlu MC, Borazan M. Limbal relaxing incisions for primary mixed astigmatism and mixed astigmatism after cataract surgery. J Cataract Refract Surg. 2003 Apr;29(4):723-8.

4. Chylack LT Jr, Leske MC, McCarthy D, Khu P, Kashiwagi T, Sperduto R. Lens opacities classification system II (LOCS II) Arch Ophthalmol. 1989 Jul;107(7):991-7.

5. Kaufmann C, Peter J, Ooi K, Phipps S, Cooper P, Goggin M; Queen Elizabeth Astigmatism Study Group. Limbal relaxing incisions versus on-axis incisions to reduce corneal astigmatism at the time of cataract 
surgery. J Cataract Refract Surg. 2005 Dec;31(12):2261-5.

6. Ferrer-Blasco T, Montés-Micó R, Peixoto-de-Matos SC, González-Méijome JM, Cerviño A. Prevalence of corneal astigmatism before cataract surgery. J Cataract Refract Surg. 2009 Jan;35(1):70-5. doi: 10.1016/j.jcrs.2008.09.027.

7. Eliwa TF, Abdellatif MK, Hamza II. Effect of Limbal Relaxing Incisions on Corneal Aberrations. J Refract Surg. 2016 Mar;32(3):156-62. doi: 10.3928/1081597X20160121-02.

8. Gibbons A. Use of a Toric Intraocular Lens and a Limbal-Relaxing Incision for the Management of
Astigmatism in Combined Glaucoma and Cataract Surgery. Case Reports in Ophthalmology. 2016 Feb 23;7(1):96-102. DOI:10.1159/000444213.

9. Hashemi H, Khabazkhoob M, Soroush S, Shariati R, Miraftab M, Yekta A. The location of incision in cataract surgery and its impact on induced astigmatism. Curr Opin Ophthalmol. 2016 Jan;27(1):58-64. doi: 10.1097/ICU.0000000000000223.

10. Mohammad-Rabei H, Mohammad-Rabei E, Espandar G, Javadi MA, Jafarinasab MR, Hashemian SJ, Feizi S. Three methods for correction of astigmatism during phacoemulsification. Journal of Ophthalmic \& Vision Research. 2016 Apr;11(2):162. doi: 10.4103/2008-322X.183924.

\section{How to cite this article?}

K. Ravikumar, M. Arthi, Rajakumari. A study on efficacy of limbal relaxing incisions in correcting corneal astigmatism along with clear corneal phacoemulsification in a tertiary eye care centre in South India. Int J Med Res Rev 2017;5(02):168-175. doi:10.17511/ijmrr. 2017.i02.12. 